\title{
Market States and Momentum
}

\author{
MICHAEL J. COOPER, ROBERTO C. GUTIERREZ JR., \\ and ALLAUDEEN HAMEED*
}

\begin{abstract}
We test overreaction theories of short-run momentum and long-run reversal in the cross section of stock returns. Momentum profits depend on the state of the market, as predicted. From 1929 to 1995, the mean monthly momentum profit following positive market returns is $0.93 \%$, whereas the mean profit following negative market returns is $-0.37 \%$. The up-market momentum reverses in the long-run. Our results are robust to the conditioning information in macroeconomic factors. Moreover, we find that macroeconomic factors are unable to explain momentum profits after simple methodological adjustments to take account of microstructure concerns.
\end{abstract}

Several Behavioral theOries have been developed to jointly explain the shortrun cross-sectional momentum in stock returns documented by Jegadeesh and Titman (1993) and the long-run cross-sectional reversal in stock returns documented by DeBondt and Thaler (1985). ${ }^{1}$ Daniel, Hirshleifer, and Subrahmanyam (1998; hereafter DHS) and Hong and Stein (1999; hereafter HS) each employ different behavioral or cognitive biases to explain these anomalies. ${ }^{2,3}$

\footnotetext{
*Cooper is from the Krannert Graduate School of Management, Purdue University. Gutierrez is from the Lundquist College of Business, University of Oregon. Hameed is from the NUS Business School, National University of Singapore. We gratefully acknowledge financial support from the John and Mary Willis research award (Cooper), a Summer Research Grant from the Department of Finance at Texas A\&M (Gutierrez), and an Academic Research Grant from the National University of Singapore (Hameed). We thank Kent Daniel, Ken French, Simon Gervais, Eric Ghysels, Christo Pirinsky, Bhaskaran Swaminathan, and seminar participants at the University of Colorodo, University of Utah, and University of Virginia for their helpful discussions. Comments from the editor, Rick Green, and an anonymous referee are also gratefully acknowledged. Any errors are our own.

${ }^{1}$ We use the phrase "short-run" to refer to six- to twelve-month momentum for ease of exposition. Note that the behavioral models do not address the shorter-run evidence of reversal at the weekly horizon (Lehmann (1990), Lo and MacKinlay (1990), Cooper (1999)).

${ }^{2}$ Our understanding is that the predictions of the Barberis, Shleifer, and Vishny (1998) model for momentum profits conditioned on the state of the market are difficult to assess, which is the central test of our study as we soon discuss. In their model, individuals typically overreact (underreact) to low-weight, high-strength news (high-weight, low-strength news). Testing this model requires identifying and characterizing news in terms of their "strength" and "weight".

${ }^{3}$ The three-factor model of Fama and French (1996) can explain long-run reversal but not shortrun momentum. Ahn, Conrad, and Dittmar (2002) and Yao (2002) employ nonparametric methods and show that systematic factors explain momentum. To the extent that mispricings are systematic, however, the basis assets themselves may also be capturing irrationalities (Hirshleifer (2001)). Additionally, Lee and Swaminathan (2000) show that trading volume plays a role in the profits to momentum strategies, which they interpret to mean that prices generally deviate from fundamental values. Grinblatt and Moskowitz (2003) conclude that tax environments affect the profits to
} 
Following these models, we test the theory that overreaction is the source of these return patterns.

DHS assume that investors are overconfident about their private information and overreact to it. If investors also have a self-attribution bias, then when subsequent (public) information arrives, investors will react asymmetrically to confirming versus disconfirming pieces of news. In other words, investors attribute successes to their own skill more than they should and attribute failures to external noise more than they should. The consequence of this behavior is that investors' overconfidence increases following the arrival of confirming news. The increase in overconfidence furthers the initial overreaction and generates return momentum. The overreaction in prices will eventually be corrected in the long-run as investors observe future news and realize their errors. Hence, increased overconfidence results in short-run momentum and long-run reversal.

The theory of DHS can be extended to predict differences in momentum profits across states of the market. Aggregate overconfidence should be greater following market gains (DHS and Gervais and Odean (2001)). Since investors in aggregate hold long positions in the equity market, increases in market prices will tend to be attributed unduly to investor skill and will result in greater aggregate overconfidence. If overconfidence is in fact higher following market increases, then the overreactions will be stronger following these up markets generating greater momentum in the short-run.

HS also develop a behavioral theory to explain momentum. Their model is based on initial underreaction to information and subsequent overreaction, which eventually leads to stock price reversal in the long-run. The HS model employs two types of investors: "newswatchers" and "momentum traders." The newswatchers rely exclusively on their private information; momentum traders rely exclusively on the information in past price changes. The additional assumption that private information diffuses only gradually through the marketplace leads to an initial underreaction to news. ${ }^{4}$ The underreaction and subsequent positive serial correlation in returns attracts the attention of the momentum traders whose trading activity results in an eventual overreaction to news. Prices revert to their fundamental levels in the long-run.

This model also predicts relative changes in price dynamics depending on the state of the market. HS examine the effect of changing the risk aversion of momentum traders. In their Figure 2, they found that decreasing risk aversion led to greater delayed overreaction, and therefore, to increased momentum profits. To the extent that risk aversion decreases as wealth increases (as suggested by Campbell and Cochrane (1999), Barberis, Huang, and Santos (2001), and

both momentum and contrarian strategies. Lesmond, Schill, and Zhou (2002) and Korajczyk and Sadka (2002) question if momentum profits are realizable given trading costs. Finally, the concern for a data-snooping bias seems small given the foreign-market evidence of Rouwenhorst (1998) and the 1990s United States evidence of Jegadeesh and Titman (2001).

${ }^{4}$ Holden and Subrahmanyam (2002) also develop a model that generates momentum through the gradual diffusion of information. 
others), this model also predicts that momentum profits will be greater following market gains.

We examine whether conditioning on the state of the market is important to the profitability of momentum strategies. We define two states: (1) "UP" is when the lagged three-year market return is non-negative, and (2) "DOWN" is when the three-year lagged market return is negative. We find that short-run momentum profits exclusively follow UP periods. From 1929 through 1995, the six-month momentum strategy generates a significant mean monthly profit of $0.93 \%$ after three-year UP markets and an insignificant $-0.37 \%$ profit after three-year DOWN markets. Furthermore, these profits are significantly different, and these results are robust using one-year and two-year lagged market states and risk adjustments. Hence, consistent with DHS and HS, the state of the market is critically important to the profitability of momentum strategies.

A central prediction of the overreaction theory is that the momentum profits will reverse in the long-run as the market eventually corrects the mispricings. Similar to the unconditional results in Lee and Swaminathan (2000) and Jegadeesh and Titman (2001), we find that UP-market momentum profits do significantly reverse in the long-run. The mean return spread between prior winners and losers over holding-period months 13 to 60 is reliably negative at $-0.36 \%$ per month following UP market states. So when there is momentum, there is ultimately long-run reversal.

Interestingly, we also find significant long-run reversal following DOWN states as well, despite the absence of DOWN-state momentum in the shortrun. This finding is not necessarily inconsistent with the overreaction theories of momentum, since there may be other factors causing long-run reversal in general. For example, it may be that cyclical variations in risk drive a portion of the long-run reversal. While we are sympathetic with the intuition behind time variation in risk, it is important to note that there is concern over how to model such variation. Ghysels (1998) forcefully shows that popular methods of modeling variation in risk do not lead to improvements over static risk models. ${ }^{5}$ One implication of our findings is that long-run reversals are not solely due to the corrections of prior momentum. Although overreaction does not seem to entirely explain the lagged-return anomalies, it does seem to explain a large portion of the momentum and reversal patterns.

The finding that momentum is dependent on the state of the market seems related to the recent evidence of Chordia and Shivakumar (2002; hereafter CS) that commonly used macroeconomic instruments for measuring market conditions can explain a large portion of momentum profits. CS argue that intertemporal variations in the macroeconomic factors (and presumably risk)

\footnotetext{
${ }^{5}$ Additionally, there are other psychological biases that might explain long-run reversal following DOWN states. Specifically, Daniel, Hirshleifer, and Teoh (2002) note that investors might have a salience bias. Given the increased coverage the media gives to the stock market during recessions, investors may tend to overreact to news in these bad times, only because of the greater saliency of the news.
} 
are the main sources of momentum profits. We examine if such a multifactor model can explain the asymmetry in momentum profits across UP and DOWN markets. Dividend yield, default spread, term spread, and short-term interest rates do not capture the asymmetry in momentum profits. Additional tests indicate that the success of the macroeconomic multifactor model in explaining momentum documented by CS is not robust to common screens used to mitigate microstructure-induced biases. Specifically, the employment of a onedollar price screen (to remove highly illiquid and high-trading-cost stocks) or the skipping of the month between the formation period and the trading period (to minimize spurious negative autocorrelation due to bid-ask bounce) reverses the findings of CS that the macroeconomic model can explain momentum. ${ }^{6}$

In addition, we consider if the market state is informative about momentum profits beyond the two-state, UP and DOWN, conditioning set we initially consider. In other words, we examine if momentum profits are greatest when the market's state is highest. There is a nonlinear relation between momentum profits and lagged market states. As the lagged market return increases, momentum increases and reaches a peak near the median level of market performance, slowly declining thereafter. When the lagged market return is highest, however, there remain significant momentum profits. We discuss potential explanations of this nonlinearity. Lastly, using a recursive out-of-sample procedure, we find that the lagged return on the market is a robust predictor of the time-series of momentum profits, while the macroeconomic multifactor model is not.

In sum, the state of the market measured using the lagged market return contains information about the profitability of momentum strategies. The remaining sections are organized as follows. Section I details the data and methodology and presents the momentum profits in the short-run and long-run across UP and DOWN market states; Section II provides several robustness checks and additional discussions of the main findings, including controlling for a macroeconomic factor model similar to Chordia and Shivakumar (2002); and Section III concludes the paper.

\section{Analysis of Profits across States}

\section{A. Data and Method}

The data for the study are all NYSE and AMEX stocks listed on the CRSP monthly file. Our sample period covers January 1926 to December 1995. Stocks are sorted at the end of each month $t$ into deciles based on their prior sixmonth returns. To mitigate bid-ask bounce effects, the formation-period sixmonth returns are calculated from $t-5$ to $t-1$, skipping month $t$. We exclude stocks with a price at the end of the formation period below $\$ 1$ to mitigate

\footnotetext{
${ }^{6}$ Jegadeesh and Titman (1993, 2001) and Fama and French (1996), among others, have employed such filters to better estimate momentum profits. Recently, Griffin, Ji, and Martin (2003) question the ability of macroeconomic models to explain momentum in foreign stock returns.
} 
microstructure effects associated with low-price stocks. The test-period profits are calculated for three holding periods, $t+1$ to $t+6, t+1$ to $t+12$, and $t+13$ to $t+60$, as follows. We define each momentum portfolio as long in the prior sixmonth winners (highest decile) and short in the prior six-month losers (lowest decile). We form a time-series of raw profits corresponding to each event month of the holding period, that is, we form 60 time-series of profits corresponding respectively to month 1 , month $2, \ldots$, month 60 . To form the CAPM and FamaFrench (1993) risk-adjusted profits, for each holding-period month, we regress the time-series of raw profits on the appropriate factors and a constant. Thus, we obtain the estimated factor loadings for each holding-period-month series. The risk-adjusted profits are

$$
r_{k t}^{\text {adj }}=r_{k t}-\sum_{i} \hat{\beta}_{i k} f_{i t}
$$

where $r_{k t}$ is the raw profit for the strategy in holding-period month $k$, for $k=$ $1,2, \ldots, 60$, in calendar month $t, f_{i t}$ is the realization of factor $i$ in calendar month $t$, and $\hat{\beta}_{i k}$ is the estimated loading of the time-series of raw profits in holding-period-month $k$ on $f_{i t}$. We use the excess return of the value-weighted market index over the one-month T-bill return as the sole factor for the CAPM risk adjustments and two additional factors, the small-minus-big return premium (SMB) and the high-book-to-market-minus-low-book-to-market return premium (HML), for the Fama-French risk adjustments. ${ }^{7}$

The monthly raw, CAPM-adjusted, or Fama-French-adjusted profits are then cumulated to form the holding-period profits (CAR):

$$
\mathrm{CAR}_{t+K_{2}}=\sum_{k=K_{1}}^{K_{2}} r_{k, t+k}^{*}
$$

where $r^{*}$ is either raw $\left(r_{k t}\right)$ or risk-adjusted $\left(r_{k t}^{\text {adj }}\right)$ profits and the $\left(K_{1}, K_{2}\right)$ pairs are $(1,6),(1,12)$, and $(13,60)$. For example, for the month of June 1980, the CAR over holding-period months 1 to 6 is the sum of the monthly raw or riskadjusted profits from January, February, March, April, May, and June of 1980, where the profit used in each of these months is from holding-period months $1,2,3,4,5$, and 6 , respectively; and the six-month momentum portfolio in this case is formed at the end of November 1979 (skipping December). The CAR performance metric above is similar to ones employed by Jegadeesh and Titman (1993, Tables VII and VIII) and Nagel (2001). Since the CARs are overlapping, we employ a heteroskedasticity-and-autocorrelation-consistent (HAC) estimate of the variance (Gallant (1987)), setting the number of lags equal to the number of overlapping months in the holding-period window $(5,11$, or 47$) .^{8}$

\footnotetext{
${ }^{7}$ We thank Ken French for providing the time-series of data for the Fama-French three-factor model. These factors are described by Fama and French (1993).

${ }^{8}$ We have replicated our tests using six-month nonoverlapping CARs (starting in January/July and March/September) and find that our results hold.
} 
As discussed earlier, the overreaction theories of DHS and HS predict greater short-run momentum profits following market gains. So at the beginning of each portfolio's testing period, we identify the state of the market. Longer horizons should capture more dramatic changes in the state of the market, but longer horizons also reduce the number of observations of changes in the market's state. For the initial discussion, we employ the return on the CRSP value-weighted index (including dividends) over the 36 months prior to the beginning of the strategy's holding period. If the market's three-year return is non-negative (negative), we define the state of the market as "UP" ("DOWN"). We also consider a two-year and a one-year definition of the market's state and discuss these results in Section II.B; the findings are robust. ${ }^{9}$

We estimate the mean profits (CAR) to the six-month momentum strategy following UP and DOWN states. To test if the mean profits are equal to zero in each state respectively, we regress the time-series of CARs on an UP dummy variable and a DOWN dummy variable, with no intercept. To test if the mean momentum profits following UP and DOWN markets are equal, we regress the time-series of CARs on an UP dummy variable and an intercept. These approaches preserve the full time-series of returns and allow us to reliably estimate the standard errors under serial correlation. Throughout the paper, we convert profits (and coefficients of reported regressions) to monthly figures by dividing by six.

Before discussing the findings, the use of the Fama-French "risk" adjustment requires discussion. Behaviorists do not interpret the Fama-French model as a rational risk model. This is because they do not interpret the book-to-market ratio as a risk measure but as a mispricing measure (see, e.g., Lakonishok, Shleifer, and Vishny (1994), Daniel and Titman (1997)). So in the context of testing behavioral models, the Fama-French alpha is arguably not useful. In fact, Fama and French (1996) show that their model captures long-run DeBondt-and-Thaler (1985) reversal, but not short-run momentum. So according to the three-factor model, there is only one anomaly in the literature: shortrun momentum. This contradicts the behavioral models that we are examining which predict short-run momentum and long-run reversal. Nevertheless, we provide the three-factor alphas for completeness and discuss them throughout. The short-run results are robust to the Fama-French adjustments, but as expected, the long-run findings differ slightly when employing the three-factor model.

\section{B. The Short-run Effects of Conditioning on the State of the Market}

The mean CARs for each profit series (raw, CAPM-adjusted, and FamaFrench adjusted) are reported in Table I for the portfolios formed in UP and DOWN markets, respectively. During 1929:01 to 1995:12, following UP markets, the raw and the CAPM profits in Panel A are statistically positive for the

\footnotetext{
${ }^{9} \mathrm{We}$ have also performed the analyses allowing the factor loadings in equation (1) to be different across UP and DOWN states, and the results hold.
} 
Table I

\section{Momentum Profits and Market States}

At the beginning of each month $t$, all NYSE and AMEX firms are allocated into deciles based on their lagged six-month returns (from $t-5$ to $t-1$, skipping month $t$ ). Stocks priced under $\$ 1$ at time $t$ are excluded. Non-negative (negative) returns of the VW CRSP index over months $t-$ 36 to $t-1$ define UP (DOWN) markets. Profits of the momentum portfolios (winner minus loser deciles) are cumulated across three holding periods: months $t+1$ to $t+6$, months $t+1$ to $t+$ 12 , and months $t+13$ to $t+60$. Reported below are the mean monthly profits, CAPM alphas, and Fama-French alphas over these holding periods during 1929 to 1995. Panels A and B report the profits following UP and DOWN markets, respectively. Panel C reports the robust $t$-statistics (Gallant (1987)) for the test of the equality of profits across UP and DOWN markets. The number of observations $(N)$ for each state is also given.

\begin{tabular}{|c|c|c|c|}
\hline & Months 1-6 & Months 1-12 & Months $13-60$ \\
\hline \multicolumn{4}{|c|}{ Panel A: Average Monthly Profits Following 36-month UP Markets } \\
\hline$N$ & 674 & 668 & 620 \\
\hline $\begin{array}{l}\text { Mean profit } \\
\quad(t \text {-statistic })\end{array}$ & $\begin{array}{c}0.93 \\
(8.41)\end{array}$ & $\begin{array}{c}0.72 \\
(9.43)\end{array}$ & $\begin{array}{c}-0.36 \\
(-3.23)\end{array}$ \\
\hline CAPM alpha & 1.12 & 0.87 & -0.28 \\
\hline$(t$-statistic) & $(9.84)$ & $(10.90)$ & $(-2.31)$ \\
\hline Fama-French alpha & 1.28 & 1.05 & -0.15 \\
\hline$(t$-statistic) & $(10.80)$ & $(11.87)$ & $(-1.77)$ \\
\hline \multicolumn{4}{|c|}{ Panel B: Average Monthly Profits Following 36-month DOWN Markets } \\
\hline$N$ & 124 & 124 & 124 \\
\hline Mean profit & -0.37 & -0.50 & -0.67 \\
\hline$(t$-statistic $)$ & $(-0.65)$ & $(-1.44)$ & $(-3.19)$ \\
\hline CAPM alpha & 0.01 & -0.15 & -0.51 \\
\hline$(t$-statistic $)$ & $(0.03)$ & $(-0.49)$ & $(-2.61)$ \\
\hline Fama-French alpha & 0.64 & 0.42 & -0.11 \\
\hline$(t$-statistic $)$ & $(1.44)$ & (1.69) & $(-0.76)$ \\
\hline \multicolumn{4}{|c|}{ Panel C: Test for Equality (UP - DOWN = 0) } \\
\hline Mean profit & $(2.26)$ & $(3.47)$ & (1.54) \\
\hline CAPM alpha & $(2.22)$ & $(3.22)$ & (1.19) \\
\hline Fama-French alpha & $(1.4)$ & $(2.36)$ & $(-0.29)$ \\
\hline
\end{tabular}

six-month strategy during the first six months of the holding period (termed the " $6 / 6$ strategy") and are $0.93 \%$ and $1.12 \%$ per month, respectively. The raw and CAPM profits for the six-month strategy during the first 12 months of the holding period (termed the " $6 / 12$ strategy") are $0.72 \%$ and $0.87 \%$ per month and are also statistically significant.

The performance of the six-month momentum strategy is, however, dramatically different following DOWN states. In fact, in Panel B, there is no evidence of six-month momentum profits following DOWN states in either the $6 / 6$ or the $6 / 12$ strategies. The mean raw and CAPM-adjusted profits range from $-0.50 \%$ to $0.01 \%$ and are not statistically different from zero in any of these cases. Conditioning on the state of the market has a clear and dramatic impact on the profits to momentum strategies. 
In Panel C, we provide the $t$-statistics for testing the equality of the profits across UP and DOWN states for the three holding periods. Momentum profits are statistically greater following UP markets using both the raw and CAPMadjusted profits for the 6/6 and 6/12 strategy. So, momentum profits are greater in the short-run following UP markets than following DOWN markets, as predicted by the overreaction theories.

Note also in Table I that there is less evidence that momentum profits are greater following UP markets than DOWN markets when using the FamaFrench model. The differences are only significant for the 6/12 strategy. But we find in Section II.B that defining the state of the market with lagged two-year or one-year market returns provides strong evidence that UP-market momentum is greater than DOWN-market momentum for the 6/6 strategy even when using the three-factor model. The asymmetry in short-run momentum profits is robust to Fama-French (FF) alphas.

\section{The Long-Run Reversal in the Profits to Momentum Strategies}

If the short-run momentum profits are an overreaction to news, then we expect to see long-run reversal of the profits to the six-month strategy as the market eventually corrects the mispricings. Lee and Swaminathan (2000) and Jegadeesh and Titman (2001) examine the unconditional mean profits to the six-month momentum strategy over a five-year holding period and find that the profits reverse in years two to five-consistent with overreaction and correction. Figures 1 and 2 plot the cumulative raw and CAPM profits, respectively, to the six-month momentum strategy following UP and DOWN states in holding-period months 1 to 60. The UP-market plots of the raw and CAPM profits are consistent with the unconditional findings of Lee and Swaminathan

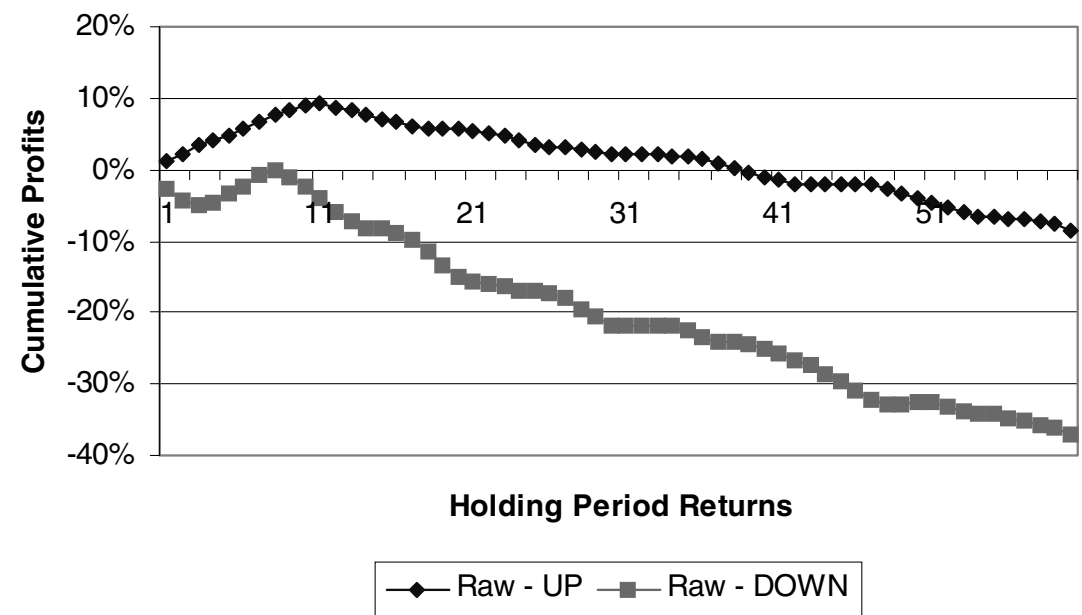

Figure 1. Cumulative raw profits in UP and DOWN states. The cumulative mean monthly profits over the months $t+1$ to $t+60$ are plotted for the six-month momentum strategy from 1929:01 to 1995:12 following three-year UP markets and three-year DOWN markets, respectively. 


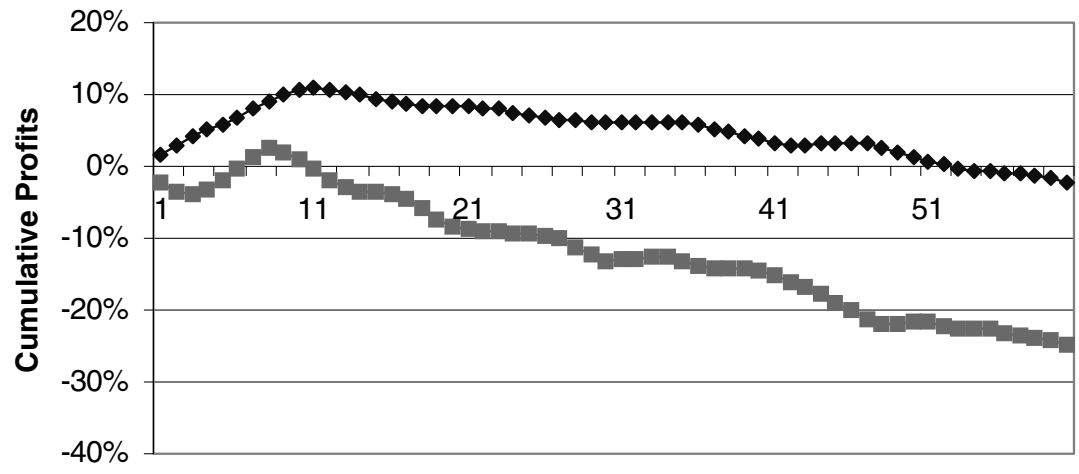

Holding Period Returns

$\multimap$ CAPM - UP $\rightarrow$ CAPM - DOWN

Figure 2. Cumulative CAPM profits in UP and DOWN states. The cumulative CAPM alphas over the months $t+1$ to $t+60$ are plotted for the six-month momentum strategy from 1929:01 to 1995:12 following three-year UP markets and three-year DOWN markets, respectively.

and Jegadeesh and Titman in that the early momentum profits are offset by subsequent long-run reversal.

The last column of Table I provides a formal test of the significance of the longrun reversal in the profits. Following UP markets, there is significant evidence of reversal in the six-month strategy's profits in months 13 to 60 ; both the raw and CAPM-adjusted profits are reliably negative. Again, this is consistent with an initial overreaction and subsequent correction.

As discussed earlier, the FF alphas are expected to display less evidence of long-run reversal. Figure 3 shows this to be the case. But we still can reject in Table I the null hypothesis of zero abnormal returns in the long-run following UP markets even using the FF method, with a $t$-statistic of -1.77 .

Figures 1 and 2 also indicate that the overreaction theory does not capture the entire long-run anomaly however. We see strong long-run reversal in the raw and in the CAPM-adjusted profits of the six-month strategy, despite there being no early momentum. The average raw and CAPM-adjusted profits during months 13 to 60 in DOWN states are significantly negative at $-0.67 \%$ and $-0.52 \%$, respectively. Long-run reversal can apparently exist without shortrun momentum. While overreaction cannot completely explain the short-run momentum and long-run reversal phenomena, overreaction does seem capable of explaining a large portion of the lagged-return anomalies.

\section{Robustness and Other Considerations}

\section{A. Can a Macroeconomic Factor Model Explain These Patterns?}

Chordia and Shivakumar (2002; hereafter CS) show that commonly-used macroeconomic instruments for measuring market conditions can explain a 


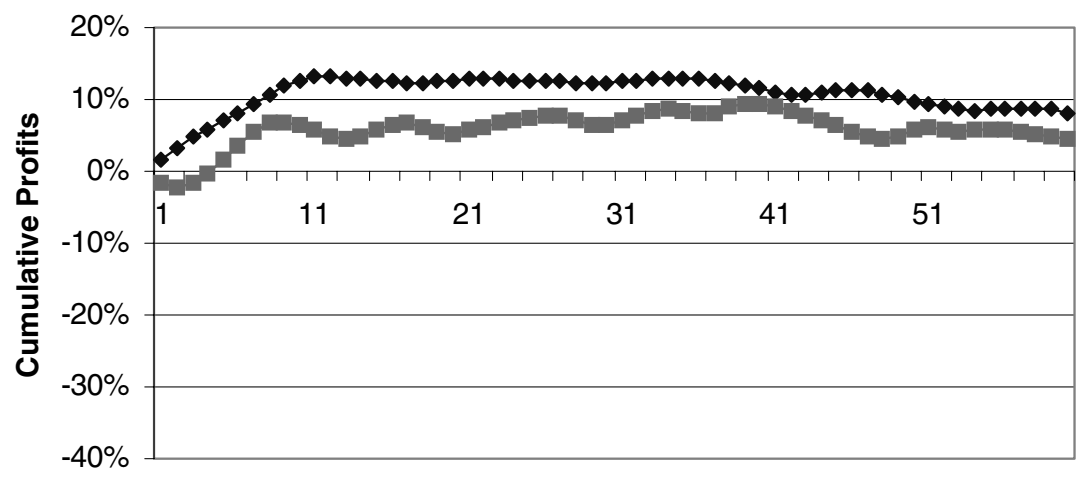

Holding Period Returns

$\longrightarrow$ FF - UP $\rightarrow-F F$ - DOWN

Figure 3. Cumulative Fama-French profits in UP and DOWN states. The cumulative Fama-French three-factor alphas over the months $t+1$ to $t+60$ are plotted for the six-month momentum strategy from 1929:01 to 1995:12 following three-year UP markets and three-year DOWN markets, respectively.

large portion of six-month momentum profits. CS show that, after controlling for cross-sectional differences in returns predicted using lagged macroeconomic variables, the portfolios of past winners and past losers do not exhibit shortterm return momentum. They conclude that the profitability of momentum strategies can be attributed to variations in the macroeconomic factors (and presumably to risk). We examine if such a macroeconomic model can capture the asymmetries that we find in the profits to the six-month momentum strategy. In other words, is the lagged market return a proxy for changes in the macroeconomic variables considered by CS?

The return-generating model that CS employ is

$$
r_{t}=a+b_{1} \mathrm{DIV}_{t-1}+b_{2} \mathrm{DEF}_{t-1}+b_{3} \mathrm{TERM}_{t-1}+b_{4} \mathrm{YLD}_{t-1}+e_{t}
$$

where $r_{t}$ is the return of stock $i$ in month $t, a$ and $b_{k}(k=1, \ldots, 4)$ are coefficients, $e_{t}$ is the error term, $\mathrm{DIV}_{t-1}$ is the lagged dividend yield of the CRSP valueweighted index, $\mathrm{DEF}_{t-1}$ is the lagged yield spread between Baa-rated bonds and Aaa-rated bonds, TERM $_{t-1}$ is the lagged yield spread between ten-year Treasury bonds and six-month Treasury bills, and $\mathrm{YLD}_{t-1}$ is the lagged yield on a T-bill with three months to maturity. ${ }^{10}$

To see the extent to which the macroeconomic multifactor model can explain the profits of the momentum strategies, we employ two-way dependent sorts as CS do. We first sort all stocks each month into quintiles based on their predicted returns from the factor model, and then we sort each of these quintiles

\footnotetext{
${ }^{10}$ We thank Jeff Pontiff for providing the macroeconomic data used by Pontiff and Schall (1998).
} 
further (into quintiles) based on the lagged six-month returns of the stocks. The predicted returns from the factor model are calculated as follows.

The loadings for each stock on the four macroeconomic factors are calculated with a time-series regression of stock returns on the four factors and an intercept using months $t-59$ to $t$. The loadings are updated monthly. We require that each stock have a minimum of 12 observations within the 60-month window. We calculate the monthly predicted returns (fitted values from the model using lagged factor realizations and coefficient estimates) for all stocks and compound these predictions into a six-month factor-model predicted return from $t+1$ to $t+6$. Stocks are then sorted into quintiles based on their six-month predicted returns, and each of these quintiles is further sorted into quintiles based on lagged six-month returns ( $t-5$ to $t-1$, skipping month $t$ ). The raw monthly returns to each of the 25 portfolios are cumulated over months $t+1$ to $t+6$ to form CARs as before and are separated into three-year UP and DOWN markets at time $t$. The mean profits to these 25 portfolios are calculated and reported for each state. Finally, the mean profits to a strategy that buys the winner lagged-return quintile and sells the loser lagged-return quintile within each of the predicted-return quintiles is also reported.

Unlike CS, who sort on formation-period predicted returns, we first sort on predicted returns constructed using realized factor values from the holding period. We contend that the latter window is more appropriate in determining whether the macroeconomic model explains the return patterns (and should yield a test with greater power). This is analogous to employing the realized market return to determine if the CAPM explains a given stock's return behavior.

With these two-way sorts, we can examine if the cross-sectional variation in returns predicted by the macroeconomic factor model captures conditional variation in the momentum profits. In Table II, we present the mean profits for the two-way sorts from 1929 to 1995 . Panel A shows that the macroeconomic model has no ability to explain the momentum profits following UP states. The level of the momentum profits within each quintile of the factor-model predicted returns is at least $0.50 \%$ per month, and all mean profits are significantly different from zero. As expected, following DOWN states, Panel B shows no evidence of momentum within the predicted-return quintiles. In contrast to $\mathrm{CS}$, the macroeconomic model shows little, if any, ability to capture momentum profits.

To understand what drives the difference between our findings and those of CS, we first replicate their method (on unconditional profits). Using (1) the 1963:07 to 1994:12 data, (2) with formation-period predicted returns, (3) with no price screen, (4) without skipping the last month of the six-month laggedreturn measure of momentum, and (5) employing the nonoverlapping return method of Jegadeesh and Titman (1993), we are able to reproduce the findings of CS reported in Panel B of their Table VII. As shown in Panel A of our Table III, we also find that the multifactor model captures the unconditional momentum profits in the four lowest quintiles of predicted returns. The ability of the macroeconomic model to capture momentum profits, however, is strongly 
Table II

\section{Two-Way Dependent Sorts: Six-Month Factor-Model Predicted Returns and Then Lagged Six-Month Returns in UP and DOWN States}

All NYSE and AMEX stocks are first sorted each month $t$ into quintiles based on their six-month $(t+1$ to $t+6)$ predicted returns from the four-factor model: lagged dividend yield of CRSP valueweighted index (DIV), lagged yield spread for Baa bonds over Aaa bonds (DEF), lagged yield spread for 10-year Treasury over three-month Treasury (TERM), and lagged yield on a T-bill with three months until maturity (YLD). Stocks priced under $\$ 1$ at time $t$ are excluded. Each predicted-return quintile is then further sorted into quintiles based on lagged six-month returns $(t-5$ to $t-1$, skipping month $t$ ). Non-negative (negative) returns of the VW CRSP index during months $t-36$ to $t-1$ define UP (DOWN) markets. Returns of the 25 portfolios are cumulated across months $t+1$ to $t+6$. In Panel A (B), we report the mean monthly returns following UP (DOWN) markets from 1929 to 1995. The "High-Low" column provides the mean profits of the strategy that buys the winner quintile and sells the loser quintile within each predicted-return quintile (across each row). The robust $t$-statistics (Gallant (1987)) on the profits to this strategy are given in the last column. The "ALL" column reports the mean returns in each predicted-return quintile. The number of observations $(N)$ for each state is also given.

\begin{tabular}{lcccccccc}
\hline & \multicolumn{7}{c}{ Lagged Six-Month Returns } \\
\cline { 2 - 8 } $\begin{array}{l}\text { Macro-Model } \\
\text { Predicted Returns }\end{array}$ & Low & 2 & 3 & 4 & High & ALL & High-Low & $\begin{array}{c}t \text {-Stat } \\
\text { (High-Low) }\end{array}$ \\
\hline \multicolumn{7}{c}{ Panel A: Average Monthly Returns } & Following $36-$-month UP Markets $(N=674)$ \\
\hline Low & 0.49 & 0.80 & 0.89 & 1.05 & 1.14 & 0.87 & 0.65 & 5.89 \\
2 & 0.68 & 0.92 & 1.01 & 1.08 & 1.19 & 0.98 & 0.51 & 6.26 \\
3 & 0.78 & 0.93 & 1.02 & 1.09 & 1.28 & 1.02 & 0.50 & 6.18 \\
4 & 0.77 & 0.96 & 1.03 & 1.10 & 1.32 & 1.04 & 0.55 & 6.64 \\
High & 0.70 & 0.97 & 1.08 & 1.19 & 1.31 & 1.05 & 0.62 & 6.51 \\
\hline & Panel B: Average Monthly Returns Following $36-$ month DOWN Markets $(N=124)$ \\
\hline Low & 3.29 & 3.15 & 3.02 & 2.86 & 2.77 & 3.02 & -0.51 & -1.22 \\
2 & 3.25 & 2.69 & 2.35 & 2.30 & 1.17 & 2.35 & -0.91 & -2.20 \\
3 & 2.81 & 2.36 & 2.06 & 2.10 & 2.32 & 2.33 & -0.48 & -1.22 \\
4 & 2.24 & 2.10 & 2.03 & 1.94 & 2.30 & 2.12 & 0.07 & 0.17 \\
High & 2.29 & 2.29 & 1.98 & 2.29 & 2.85 & 2.34 & 0.57 & 1.37 \\
\hline
\end{tabular}

affected by methodological adjustments commonly used in the momentum literature to mitigate microstructure concerns. Specifically, when we exclude from the portfolios stocks priced under $\$ 1$ at the beginning of the testing period (to eliminate highly illiquid and high-trading-costs stocks) and skip the last month between the formation period and the holding period in constructing the momentum measure (to reduce spurious reversal due to bid-ask bounce), the results change. Jegadeesh and Titman (1993, 2001) and Fama and French (1996), among others, have employed such adjustments to mitigate the microstructure concerns and thereby better estimate momentum profits. As reported in Panel B of Table III, the application of these adjustments results in significant momentum profits in four of the five quintiles of predicted returns. The predominant effect of these adjustments is to lower the returns in the lowest quintile of 


\section{Table III}

\section{Two-Way Dependent Sorts: Six-Month Factor-Model Predicted Returns and Then Lagged Six-Month Returns}

All NYSE and AMEX stocks are first sorted each month $t$ into quintiles based on their six-month $(t-5$ to $t$ ) predicted returns from the four-factor model: lagged dividend yield of CRSP valueweighted index, lagged yield spread for Baa bonds over Aaa bonds, lagged yield spread for 10-year Treasury over three-month Treasury, and lagged yield on a T-bill with three months until maturity. In Panel A, each predicted-return quintile is then further sorted into quintiles based on lagged six-month returns (from $t-5$ to $t$, including month $t$ ); no low-price stocks are excluded. Panel B employs lagged returns from months $t-5$ to $t-1$, skipping month $t$, as the second sort and excludes stocks priced below $\$ 1$ at time $t$. We report the mean monthly returns for these 25 portfolios over the holding-period months $t+1$ to $t+6$ for the period 1963:07 to 1994:12 (the sample period of Chordia and Shivakumar (2002)). The "High-Low" column provides the mean returns of the strategy that buys the winner quintile and sells the loser quintile within each predicted-return quintile (across each row). This table employs the nonoverlapping-return method used by Chordia and Shivakumar (2002). The "ALL" column reports the mean monthly returns in each predicted-return quintile.

\begin{tabular}{lcccccccc}
\hline & \multicolumn{7}{c}{ Lagged Six-Month Returns } \\
\cline { 2 - 8 } $\begin{array}{l}\text { Macro-Model } \\
\text { Predicted Returns }\end{array}$ & Low & 2 & 3 & 4 & High & ALL & High-Low & $\begin{array}{c}t \text {-Stat } \\
\text { (High-Low) }\end{array}$ \\
\hline \multicolumn{8}{c}{ Panel A: Average Monthly Returns } \\
(formation-period predicted returns, no price screen, not skipping month $t$ ) \\
\hline Low & 0.90 & 0.97 & 1.05 & 1.08 & 1.10 & 1.02 & 0.20 & 0.63 \\
2 & 1.08 & 1.18 & 1.09 & 1.14 & 1.26 & 1.15 & 0.18 & 0.96 \\
3 & 1.16 & 1.25 & 1.26 & 1.25 & 1.30 & 1.24 & 0.14 & 0.80 \\
High & 1.35 & 1.41 & 1.46 & 1.43 & 1.59 & 1.45 & 0.25 & 1.39 \\
\hline & 1.36 & 1.47 & 1.54 & 1.65 & 1.82 & 1.57 & 0.46 & 2.28 \\
\hline
\end{tabular}

Panel B: Average Monthly Returns

(formation-period predicted returns, $\$ 1$ price screen, skipping month $t$ )

\begin{tabular}{lllllllll}
\hline Low & 0.23 & 0.91 & 1.01 & 1.08 & 1.18 & 0.88 & 0.95 & 4.34 \\
2 & 0.93 & 1.14 & 1.11 & 1.13 & 1.30 & 1.12 & 0.37 & 2.34 \\
3 & 1.07 & 1.22 & 1.25 & 1.25 & 1.33 & 1.22 & 0.26 & 1.62 \\
4 & 1.23 & 1.44 & 1.46 & 1.46 & 1.60 & 1.44 & 0.37 & 2.32 \\
High & 1.23 & 1.48 & 1.56 & 1.63 & 1.81 & 1.54 & 0.58 & 3.18 \\
\hline
\end{tabular}

lagged-six-month returns. This is consistent with the adjustments succeeding in reducing spurious negative autocorrelation. Note that applying either the price screen or the skip-month return in isolation is sufficient to reverse the CS findings. Hence, it seems that, while market conditions are critically important in determining momentum profits, the macroeconomic-based proxies for the market's state are not useful (only the lagged return of the market is). ${ }^{11}$

\footnotetext{
${ }^{11}$ We also examined several variations of the macroeconomic model, and the results do not change. We considered the predicted returns (1) without including the intercept, (2) estimating factor loadings using a two-year window instead of a five-year one, (3) using portfolio loadings (from 50 size portfolios) as proxies for individual stock loadings, and (4) using a multiple-stepahead forecast from the macro model to predict holding-period returns using only information available at time $t$.
} 


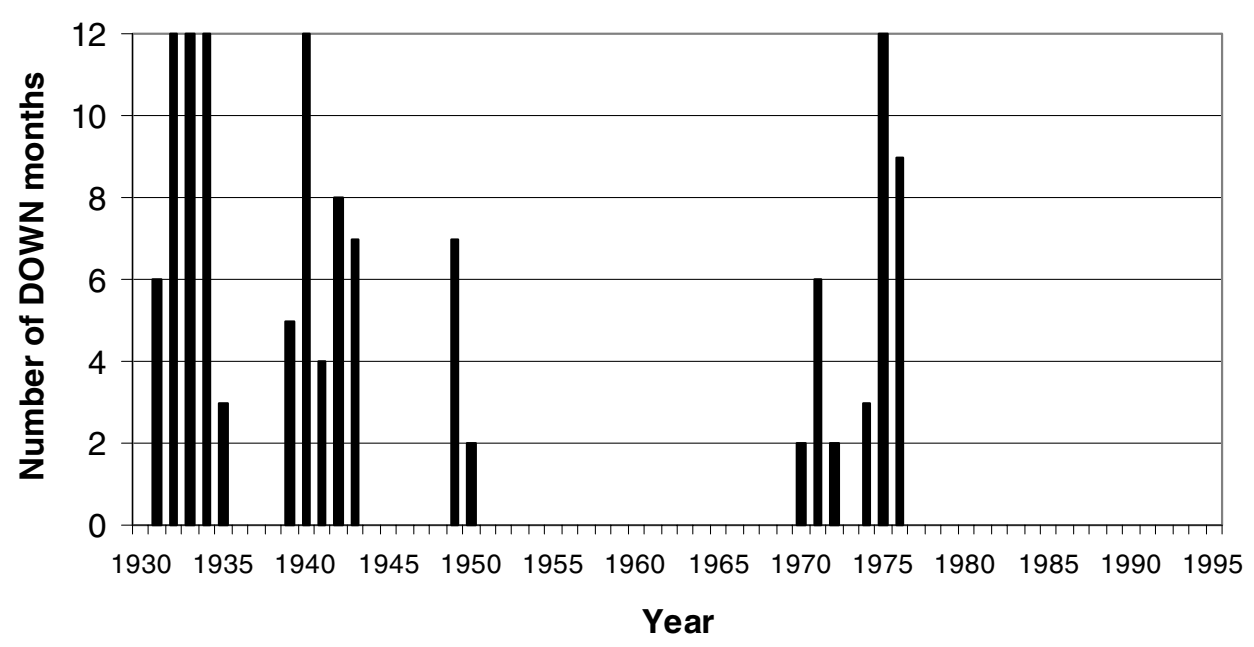

Figure 4. Number of three-year DOWN states through time. The number of months within a given year for which the holding-period return of the VW CRSP index over months $t-36$ to $t-1$ is negative during 1929 to 1995.

\section{B. Other Horizons for Measuring the Market's State}

In the previous analyses, we employ the three-year return on the market as the state proxy. As we noted before, longer horizons should capture greater differences in market states, but longer horizons also yield fewer observations of DOWN states (124 out of 798 months using the lagged three-year market return). We plot the number of DOWN months in each year from 1929 to 1995 for the lagged 36-month VW index in Figure 4, and the number of DOWN months in each year for the lagged 12-month VW index in Figure 5. The number of DOWN states increases as the number of months defining the market's state decreases. In particular, the 12-month market definition produces 219 DOWN months (27\% of the sample period). The 12-month DOWN states are more dispersed across the sample period.

To verify that the conditional nature of momentum profits is evident when using less extreme definitions of DOWN states, we provide in Table IV the mean profits to the 6/6 strategy conditioning on either the lagged 12-month or the lagged 24-month return of the CRSP VW index. In Panel A, the UP-market raw, CAPM, and Fama-French profits are significant and are all above 0.99\% per month for each alternative state proxy. In Panel B, the DOWN-market raw and CAPM profits are again all indistinguishable from zero. ${ }^{12}$ Panel $\mathrm{C}$ shows that the momentum profits for all three profit specifications are statistically greater following UP markets than following DOWN markets using both alternative state proxies. In sum, our finding that momentum profits are

\footnotetext{
12 The Fama-French profits display evidence of DOWN-market momentum using the 12-month definition of the market's state.
} 


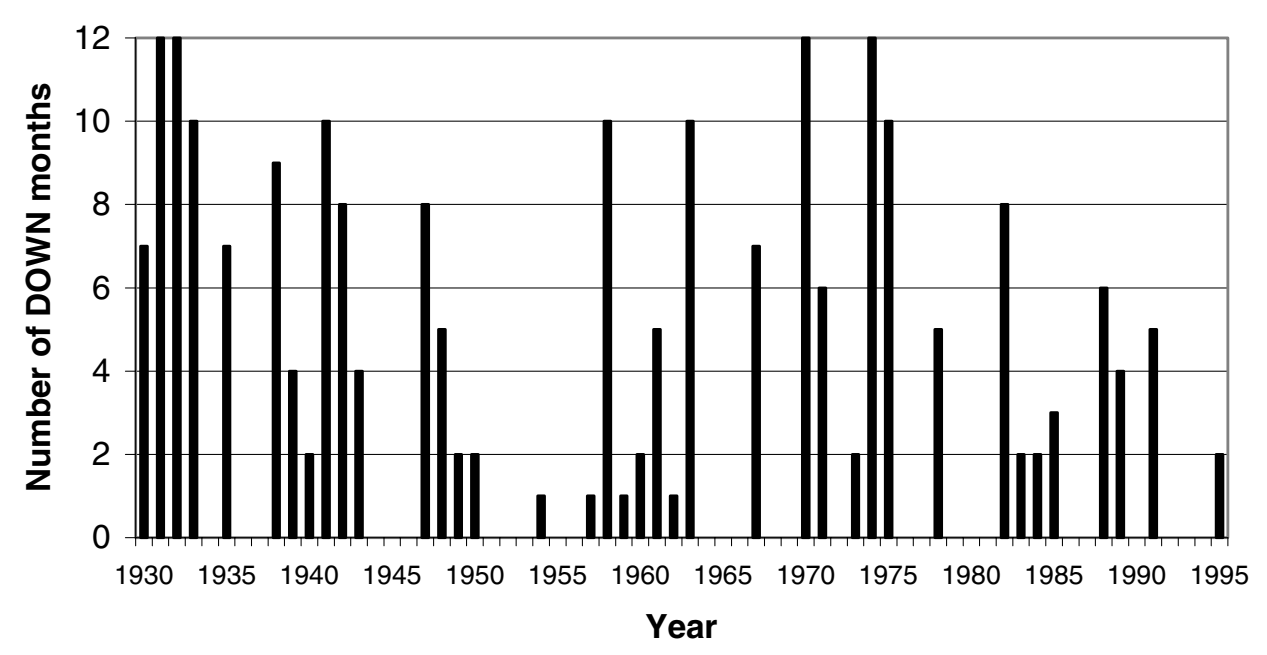

Figure 5. Number of one-year DOWN states through time. The number of months within a given year for which the holding-period return of the VW CRSP index over months $t-12$ to $t-1$ is negative during 1929 to 1995.

critically dependent on the state of the market is robust to using lagged twoyear or lagged one-year market returns as the proxy for the market's state.

\section{The Market's State as a Continuous Variable}

We also examine the relation between the lagged market return and momentum profits using the market's return as a continuous variable, not just the discrete UP and DOWN states as before. In particular, we are interested if momentum profits increase monotonically with the lagged market return. When the lagged market return is highest, are momentum profits the greatest?

To determine this, we regress momentum profits on lagged market returns as well as the square of lagged market returns. We report the results using the lagged 36-month market return as the state proxy (the 12-month and 24-month results are similar). As shown in Panel A of Table V, the raw and risk-adjusted profits are positively related to lagged market returns, confirming our finding that momentum is high (low) when lagged market return is high (low). Interestingly, the profits are negatively related to the square of lagged market returns, indicating that profits do not increase linearly with lagged market returns. ${ }^{13}$ In Panel B, we report the momentum profits ranking the market's 36-month lagged returns into quintiles. We see that profits increase

\footnotetext{
${ }^{13}$ Jegadeesh and Titman (1993) also examine the relation between momentum profits and the square of the lagged market return. However, since their intent is to examine if lead-lag effects are a source of momentum profits, they employ the lagged market return over the six-month formation period of the momentum portfolios. They find a negative coefficient on the squared market return and conclude that this is inconsistent with lead-lag effects contributing to momentum profits.
} 


\section{Table IV}

\section{Momentum Profits and Alternative Definitions of Market States}

At the beginning of each month $t$, all NYSE and AMEX firms are allocated into deciles based on their lagged-six-month returns (from $t-5$ to $t-1$, skipping month $t$ ). Stocks priced under $\$ 1$ at time $t$ are excluded. Returns on the VW CRSP index are computed over the period $t-m$ to $t-1$ (where $m=12$ or 24), and non-negative (negative) returns of the VW CRSP index define UP (DOWN) markets. Profits of the momentum portfolios (winner minus loser deciles) are cumulated across months $t+1$ to $t+6$. Reported below are the mean monthly profits, CAPM alphas, and FamaFrench alphas. The sample period is from 1929 to 1995. Panels A and B report the profits following UP and DOWN markets, respectively. Panel C reports the robust $t$-statistics (Gallant (1987)) for the test of the equality of profits across UP and DOWN markets. The number of observations $(N)$ for each state is also given.

\begin{tabular}{|c|c|c|}
\hline & 12-Month Market & 24-Month Market \\
\hline \multicolumn{3}{|c|}{ Panel A: Average Monthly Profits Following UP Markets } \\
\hline$N$ & 579 & 667 \\
\hline $\begin{array}{l}\text { Mean profit } \\
(t \text {-statistic })\end{array}$ & $\begin{array}{c}1.04 \\
(9.23)\end{array}$ & $\begin{array}{c}0.99 \\
(9.53)\end{array}$ \\
\hline CAPM alpha & 1.22 & 1.18 \\
\hline$(t$-statistic) & $(10.42)$ & $(10.88)$ \\
\hline Fama-French alpha & 1.37 & 1.32 \\
\hline$(t$-statistic) & $(11.01)$ & $(11.71)$ \\
\hline \multicolumn{3}{|c|}{ Panel B: Average Monthly Profits Following DOWN Markets } \\
\hline$N$ & 219 & 131 \\
\hline Mean profit & -0.08 & -0.55 \\
\hline$(t$-statistic $)$ & $(-0.22)$ & $(-0.99)$ \\
\hline CAPM alpha & 0.22 & -0.21 \\
\hline$(t$-statistic) & $(0.72)$ & $(-0.45)$ \\
\hline Fama-French alpha & 0.68 & 0.43 \\
\hline$(t$-statistic $)$ & $(2.42)$ & $(1.01)$ \\
\hline \multicolumn{3}{|c|}{ Panel C: Test for Equality (UP - DOWN =0) } \\
\hline Mean profit & $(3.00)$ & $(2.27)$ \\
\hline CAPM alpha & $(3.05)$ & $(2.93)$ \\
\hline Fama-French alpha & $(2.28)$ & $(2.05)$ \\
\hline
\end{tabular}

dramatically from the lowest levels of lagged market returns to quintile 2. Profits continue to increase as the market state improves, but peak at the median levels of lagged market return. It is important to point out that momentum profits remain significant even at the highest levels of the market's state.

The nonlinear relation documented in Table V seems to suggest that overreactions may actually be diminishing beyond some threshold level of prior market performance. We offer two potential explanations of this phenomenon. First, it might be that the extreme levels of the market's performance are coincident with the ending of the overreaction phase and the beginning of the correctional reversals, triggered by the arrival of fundamental news. The onset of the reversals would of course diminish the momentum profits. Second, it 


\section{Table V}

\section{The Lagged Market Return as a Continuous Measure of the State of the Market}

At the beginning of each month $t$, all NYSE and AMEX firms are allocated into deciles based on their lagged-six-month returns (month $t-5$ to month $t-1$, skipping month $t$ ). Profits on the momentum portfolios (winner minus loser deciles) are cumulated across months $t+1$ to $t+6$. The six-month cumulative profits (raw, CAPM-adjusted, and Fama-French three-factor-adjusted) are regressed on an intercept, lagged 36-month market return (LAGMKT), and lagged 36-month market return squared (LAGMKT ${ }^{2}$ ). Panel A provides the monthly regression coefficients and robust $t$-statistics (Gallant (1987)). In Panel B, momentum portfolios are allocated each month $t$ into quintiles based on the full sample of lagged 36-month market returns; mean monthly momentum profits are reported along with their robust $t$-statistics.

\begin{tabular}{|c|c|c|c|c|}
\hline \multicolumn{5}{|c|}{ Panel A: 36-month Lagged Market } \\
\hline & Intercept & LAGMKT & LAGMKT $^{2}$ & $\operatorname{Adj}-R^{2}$ \\
\hline $\begin{array}{l}\text { Mean profit } \\
(t \text {-statistic })\end{array}$ & $\begin{array}{c}0.39 \\
(1.30)\end{array}$ & $\begin{array}{c}2.77 \\
(2.41)\end{array}$ & $\begin{array}{c}-2.40 \\
(-2.60)\end{array}$ & 0.10 \\
\hline $\begin{array}{l}\text { CAPM alpha } \\
(t \text {-statistic })\end{array}$ & $\begin{array}{c}0.69 \\
(2.83)\end{array}$ & $\begin{array}{l}2.33 \\
(2.38)\end{array}$ & $\begin{array}{l}-2.12 \\
(-2.65)\end{array}$ & 0.08 \\
\hline $\begin{array}{l}\text { Fama-French alpha } \\
(t \text {-statistic })\end{array}$ & $\begin{array}{l}1.07 \\
(4.70)\end{array}$ & $\begin{array}{c}1.34 \\
(1.62)\end{array}$ & $\begin{array}{l}-1.33 \\
(-2.06)\end{array}$ & 0.03 \\
\hline
\end{tabular}

Panel B: Momentum Profits by Quintiles of Lagged 36-month Market States

\begin{tabular}{cccccc}
\hline & Low & 2 & 3 & 4 & High \\
\hline Mean profit & -0.12 & 0.94 & 1.30 & 0.92 & 0.61 \\
$(t$-statistic $)$ & $(-0.27)$ & $(3.58)$ & $(8.31)$ & $(5.78)$ & $(3.14)$ \\
CAPM alpha & 0.17 & 1.22 & 1.50 & 1.19 & 0.64 \\
$(t$-statistic $)$ & $(0.43)$ & $(4.80)$ & $(8.76)$ & $(7.06)$ & $(3.05)$ \\
Fama-French alpha & 0.73 & 1.25 & 1.66 & 1.48 & 0.77 \\
$\quad(t$-statistic $)$ & $(1.97)$ & $(4.61)$ & $(10.12)$ & $(8.38)$ & $(3.69)$ \\
\hline
\end{tabular}

might be that investors are acquiring less private information in the extreme good states (to overreact to). Welch (2000) finds evidence consistent with this in his study of analyst herding. There is more herding when prior returns are highest indicating that there is less unique information in good times. ${ }^{14}$

\section{The Lagged Market Return versus the Macroeconomic Variables as Time-Series Predictors}

In Section II.A, we found that the macroeconomic factor model does not robustly capture the cross-sectional differences in returns between prior winner stocks and prior loser stocks. In this section, we consider whether the lagged market return is a better time-series predictor of momentum profits than the

\footnotetext{
${ }^{14}$ Note also that overconfidence theory does not necessarily predict a fully monotonic relation between lagged market returns and the level of overconfidence. As Gervais and Odean (2001) pointed out, overconfident investors might learn of their bias over time.
} 
popular macroeconomic factors used in equation (3). We do this by examining the recursive out-of-sample forecasts of momentum profits formed from the two competing sets of information: (1) lagged market returns, and (2) macroeconomic variables. The out-of-sample analysis complements the prior evidence on the robustness of the relation between momentum profits and the state of the market.

To simplify the out-of-sample procedure and maintain a "real-time" framework, the momentum profit series that we seek to predict is the mean profit in calendar month $\tau$ across the six momentum portfolios that are "open" in calendar month $\tau$ (Jegadeesh and Titman (1993)). The first momentum portfolio is in holding-period month one during month $\tau$, and the sixth portfolio is in holding-period month six during month $\tau$. Two out-of-sample forecasts for this times-series of momentum profits are obtained each month as follows.

The first forecast is estimated using the lagged market return and the square of the lagged market return. The second forecast is estimated using the four macroeconomic variables in equation (3), $\mathrm{DIV}_{t-1}, \mathrm{DEF}_{t-1}, \mathrm{TERM}_{t-1}$, and $\mathrm{YLD}_{t-1}$. The loadings of the momentum profits on each set of "factors" are estimated with a time-series regression of momentum profits on each separate set of factors and an intercept using calendar months $\tau-120$ to $\tau-1$ for the first forecast in January 1939. The loadings are updated monthly. We start with an initial in-sample period of 10 years, and then allow the in-sample window to expand each month as we roll through the sample. We form the predicted profits each month using the estimated loadings from the most recent in-sample regression and the lagged factor realizations.

The "lagged-market" forecasts and the "macro" forecasts are evaluated using two methods. For the first method, we regress the time-series of momentum profits on the two time-series of out-of-sample forecasts and a constant. The $t$-statistics on the slope coefficients test that the forecasts provide information about momentum profits. The second method is to compare the mean absolute errors of each forecast (MAE) to the mean absolute error of the "unconditional" forecast, which is the historical mean monthly momentum profit from the rolling in-sample windows. Finding that the MAE of the forecasts is smaller than the unconditional MAE is evidence of the extent to which momentum profits are forecastable using either the lagged-market variables or the macro variables.

As we do in the prior analyses, we examine raw, CAPM-adjusted, and FamaFrench-adjusted profits (see equation (1) for our method of adjustment). The out-of-sample results are reported in Table VI. They clearly show that the lagged market return alone possesses the ability to predict time-series variations in momentum profits. The $t$-statistics from the regressions of momentum profits on the forecasts are above 2.0 for the lagged-market forecasts in all three measures of the profit series. The $t$-statistics for the macro forecasts are small, and the coefficients are even the wrong sign. In addition, the MAE of the lagged-market forecasts is statistically smaller than the MAE of the unconditional forecast at the 5\% level or lower in all three of the profit series (using the $z$-statistics suggested by Diebold and Mariano (1995)). In fact, the 


\section{Table VI \\ The Forecasting Abilities of the Lagged Market Return versus the Macroeconomic Variables}

At the beginning of each month $t$, all NYSE and AMEX firms are allocated into deciles based on their lagged six-month returns (month $t-5$ to month $t-1$, skipping month $t$ ). In a given calendar month $\tau$, the profits to the six "open" momentum portfolios (winner minus loser deciles) are calculated. A calendar time-series of momentum profits is formed from the mean profits across the six portfolios in month $\tau$. The raw, CAPM-adjusted, and Fama-French three-factor adjusted monthly profits are regressed on an intercept, lagged 36-month market return, and the square of the lagged 36-month market return using an in-sample window of 10 years ending December 1938. The forecasted values for January 1939 from this "lagged market" model are formed. The in-sample window is expanded one month, and the forecasted momentum profits for February 1939 are formed, and so on. A timeseries of out-of-sample forecasts using the four macroeconomic variables, DIV, TERM, DEF, and YLD is formed similarly and is termed the "macro variables" model (see Table II for definitions of these variables). The "unconditional" forecasts are the rolling historical mean of the profit series. Momentum profits from 1939:01 to 1995:12 are regressed onto their forecasted values from the lagged-market model and the macro variables model in a multiple regression. The $t$-statistics of the slope coefficients for each forecast are given below. The mean absolute forecast error for each model is also given.

\begin{tabular}{llcc}
\hline & Forecast Type & $t$-Statistic & Mean Absolute Error \\
\hline Mean profit & Unconditional & -0.32 & 2.95 \\
& Lagged market & 2.04 & $2.87^{* * *}$ \\
& Macro variables & -0.79 & $3.06^{*}$ \\
CAPM alpha & Unconditional & -0.78 & 3.20 \\
& Lagged market & 2.06 & $3.13^{* * *}$ \\
Fama-French alpha & Macro variables & -1.22 & 3.26 \\
& Unconditional & -1.48 & 2.94 \\
& Lagged market & 2.37 & $2.91^{* *}$ \\
& Macro variables & -1.72 & 2.96
\end{tabular}

Note: The symbols ${ }^{* * *},{ }^{* *}$, and ${ }^{*}$ indicate that the mean absolute error is statistically different than the mean absolute error of the unconditional model at the $1 \%, 5 \%$, and $10 \%$ significance levels, respectively (using the $z$-statistic of Diebold and Mariano (1995)).

lagged-market forecasts outperform the unconditional historical mean by about 60 to 96 basis points per year. The MAE for the macro forecasts though is on average greater than the unconditional MAE in all cases, and is statistically worse than the unconditional MAE for the mean profit series. In sum, the lagged market return provides robust information about future momentum profits while the macro variables display no reliable information. ${ }^{15}$

\section{Conclusion}

We find that the profits to momentum strategies depend critically on the state of the market. A six-month momentum portfolio is profitable only

${ }^{15}$ The out-of-sample results for the macro variables are consistent with the findings in Table IV of Chordia and Shivakumar (2002) that the loadings of the momentum portfolio on the macroeconomic variables are nonstationary over time, even changing signs in some cases across subperiods. We confirm this finding of nonstationarily in the macro factor loadings. 
following periods of market gains (UP market states), consistent with the overreaction models of Daniel et al. (1998) and Hong and Stein (1999). We find that momentum profits increase as the lagged market return increases. However, at high levels of lagged market returns, the profits diminish but are not eliminated. Additionally, we reconfirm the findings of Lee and Swaminathan (2000) and Jegadeesh and Titman (2001) that momentum profits are reversed in the long-run, as predicted by the overreaction theories. We also find significant long-run reversal in the DOWN states although there is no initial momentum. This finding indicates that long-run reversal is not solely due to the corrections of prior momentum.

A multifactor macroeconomic model of returns, as used by Chordia and Shivakumar (2002), does not explain momentum profits. We find that the ability of such a model to explain momentum profits is not robust to controls for market frictions (specifically, a price screen and skip-month returns). Additionally, we find that the macroeconomic model cannot forecast the time-series of momentum profits out-of-sample, while the lagged return of the market can. Hence, we identify that the lagged return of the market is the type of conditioning information that is relevant for predicting the profitability of the momentum strategies.

Overall, our findings of asymmetries conditional on the state of the market complements the evidence of asymmetries in factor sensitivities, volatility, correlations, and expected returns found by Boudoukh, Richardson, and Whitelaw (1997), Whitelaw (2000), Perez-Quiros and Timmermann (2000), and Ang and Chen (2002). These studies indicate that models of asset pricing, both rational and behavioral, need to incorporate (or predict) such regime switches.

\section{REFERENCES}

Ahn, Dong H., Jennifer Conrad, and Robert F. Dittmar, 2002, Risk adjustment and trading strategies, Review of Financial Studies 16, 459-485.

Ang, Andrew, and Joseph Chen, 2002, Asymmetric correlations of equity portfolios, Journal of Financial Economics 63, 443-494.

Barberis, Nicholas, Ming Huang, and Tanos Santos, 2001, Prospect theory and asset prices, Quarterly Journal of Economics 116, 1-53.

Barberis, Nicholas, Andrei Shleifer, and Robert Vishny, 1998, A model of investor sentiment, Journal of Financial Economics 49, 307-343.

Boudoukh, Jacob, Matthew Richardson, and Robert F. Whitelaw, 1997, Nonlinearities in the relation between the equity risk premium and the term structure, Management Science 43, 371-385.

Campbell, John Y., and John H. Cochrane, 1999, By force of habit: A consumption-based explanation of aggregate stock market behavior, Journal of Political Economy 107, 205-251.

Chordia, Tarun, and Lakshmanan Shivakumar, 2002, Momentum, business cycle and time-varying expected returns, Journal of Finance 57, 985-1019.

Cooper, Michael, 1999, Filter rules based on price and volume in individual security overreaction, Review of Financial Studies 12, 901-935.

Daniel, Kent, David Hirshleifer, and Avanidhar Subrahmanyam, 1998, Investor psychology and investor security market under-and overreactions, Journal of Finance 53, 1839-1886.

Daniel, Kent, David Hirshleifer, and Siew Hong Teoh, 2002, Investor psychology in capital markets: Evidence and policy implications, Journal of Monetary Economics 49, 139-209. 
Daniel, Kent, and Sheridan Titman, 1997, Evidence on the characteristics of cross sectional variation in stock returns, Journal of Finance 52, 1-33.

DeBondt, Werner F. M., and Richard Thaler, 1985, Does the stock market overreact? Journal of Finance 40, 793-808.

Diebold, Francis X., and Roberto S. Mariano, 1995, Comparing predictive accuracy, Journal of Business and Economic Statistics 13, 253-263.

Fama, Eugene F., and Kenneth R. French, 1993, Common risk factors in the returns on stocks and bonds, Journal of Financial Economics 33, 3-56.

Fama, Eugene F., and Kenneth R. French, 1996, Multifactor explanations of asset pricing anomalies, Journal of Finance 51, 55-84.

Gallant, A. Ronald, 1987, Nonlinear Statistical Models (Wiley, New York).

Gervais, Simon, and Terrance Odean, 2001, Learning to be overconfident, Review of Financial Studies 14, 1-27.

Ghysels, Eric, 1998, On stable factor structures in the pricing of risk: Do time-varying betas help or hurt? Journal of Finance 53, 549-573.

Griffin, John M., Susan Ji, and J. Spencer Martin, 2003, Momentum investing and business cycle risk: Evidence from pole to pole, Journal of Finance 58, 2515-2547.

Grinblatt, Mark, and Tobias J. Moskowitz, 2003, Predicting stock price movements from past returns: The role of consistency and tax-loss selling, Journal of Financial Economics (forthcoming).

Hirshleifer, David, 2001, Investor psychology and asset pricing, Journal of Finance 56, 1533-1597.

Holden, Craig W., and Avanidhar Subrahmanyam, 2002, News, events, information acquisition, and serial correlation, Journal of Business 75, 1-32.

Hong, Hong, and Jeremy Stein, 1999, A unified theory of underreaction, momentum trading, and overreaction in asset markets, Journal of Finance 54, 2143-2184.

Jegadeesh, Narasimhan, and Sheridan Titman, 1993, Returns to buying winners and selling losers: Implications for stock market efficiency, Journal of Finance 48, 65-91.

Jegadeesh, Narasimhan, and Sheridan Titman, 2001, Profitability of momentum strategies: An evaluation of alternative explanations, Journal of Finance 56, 699-720.

Korajczyk, Robert, and Ronnie Sadka, 2002, Are momentum profits robust to trading costs? Journal of Finance 59, 1039-1082.

Lakonishok, Josef, Andrei Shleifer, and Robert W. Vishny, 1994, Contrarian investment, extrapolation, and risk, Journal of Finance 49, 1541-1578.

Lee, Charles M. C., and Bhaskaran Swaminathan, 2000, Price momentum and trading volume, Journal of Finance 55, 2017-2069.

Lehmann, Bruce, 1990, Fads, martingales, and market efficiency, Quarterly Journal of Economics 105, 1-28.

Lesmond, David A., Michael J. Schill, and Chunsheng Zhou, 2002, The illusory nature of momentum profits, Journal of Financial Economics 71, 349-380.

Lo, Andrew W., and A. Craig MacKinlay, 1990, When are contrarian profits due to stock market overeaction? Review of Financial Studies 3, 175-206.

Nagel, Stefan, 2001, Is it overreaction: The performance of value and momentum strategies at long horizons, Working paper, London Business School.

Perez-Quiros, Gabriel, and Allan Timmermann, 2000, Firm size and cyclical variations in stock returns, Journal of Finance 55, 1229-1262.

Pontiff, Jeffrey, and Lawrence D. Schall, 1998, Book-to-market ratios as predictors of market returns, Journal of Financial Economics 49, 141-160.

Rouwenhorst, K. Geert, 1998, International momentum strategies, Journal of Finance 53, 267-284.

Welch, Ivo, 2000, Herding among security analysts, Journal of Financial Economics 58, 369-396.

Whitelaw, Robert F., 2000, Stock market risk and return: An equilibrium approach, Review of Financial Studies 13, 521-547.

Yao, Tong, 2002, Systematic momentum, Working paper, University of Arizona. 